\section{The aftermath of prolonged academic institutions' closure: time to reopen safely}

\author{
Anjan Kumar Roy', Sadia Islam Mou ${ }^{2,}$, Humayun Kabir ${ }^{3}$, and Md. Kamrul Hasan ${ }^{3^{\star}}$ \\ ${ }^{1}$ Department of Nursing and Health Science, Jashore University of Science and Technology, Jashore- \\ 7408, Bangladesh \\ ${ }^{2}$ Department of Biochemistry and Molecular Biology, University of Dhaka, Dhaka- 1000, Bangladesh \\ ${ }^{3}$ Department of Public Health, North South University, Dhaka- 1229, Bangladesh
}

Bioresearch Communications

Volume 7, Issue 2, July 2021

DOI:

https://doi.org/10.3329/brc.v7i2.54379

\begin{abstract}
To minimize the outspread of COVID-19, the government announced the closure of all educational institutions on March 18, 2020, and it has continued since then. This extended break from educational institutes has affected the lives of students profoundly. Though face-to-face classes have been replaced by online classes, the effectiveness of the online learning system is impeded by poor technological infrastructure and stable internet access. Besides, important exams like board exams, university admission exams, and university semester exams have been suspended during this period resulting in session jam. Numerous students are also going through learning loss. Apart from academic loss, there have been reported augmented cases of child marriage, child labor, child abuse, malnutrition, and online abuse due to the extended shutdown. This protracted closure has also impacted students' mental health, physical activity, and behavioral changes. Hence, there have been increased incidences of depression, mental disorders, and suicides. Considering all these aspects, now both parents and students intend to recommence the in-person classes supporting the reopening of all institutes.
\end{abstract}

KEYWORDS: COVID-19, educational institutions closure, child abuse, child marriage, depression, reopening.
CORRESPONDING AUTHOR: Md. Kamrul Hasan, Department of Public Health, North South University, Plot 15, Block B, Bashundhara, Dhaka- 1229, Bangladesh. Email: kamrul.hasan11@northosouth.edu

\section{Introduction}

COVID-19, also known as SARS-CoV-2, has created havoc all around the world since its first detection in Wuhan, China, in December 2019 [1]. As of June 2, 2021, more than 170 million confirmed cases and 3 million confirmed deaths have been reported globally, according to WHO [2]. The first three COVID-19 cases were reported on March 8, 2020, in Bangladesh [1], with more than 0.8 million confirmed cases and 12660 deaths till now [3]. Like many other countries, Bangladesh has taken preventive strategies to respond to the ongoing COVID-19 situation, including the closure of all educational institutions. The government has declared the closure of all educational institutions on March 18, 2020, to diminish the outbreak of COVID-19, and since then, the closure has continued [1]. This long-term school closure has distressed students physically and mentally and affected their academic and professional ambitions [4].

The announcement of educational institute closure has disrupted the face-to-face education of 36.7 million preprimary to secondary school-going students and 3.15 million tertiary level students. This interruption in education has demonstrated devastating impressions on students' lives. Hence, many institutes have shifted their face-to-face classes to online platforms. Nevertheless, the effectiveness of online education is curtailed by constraints like lack of technological infrastructure, poor internet access, lack of internet literacy, availability of mobile networks, less social interaction, cost of internet, method of online teaching, etc. Accessibility of technological devices, internet connection, and online platform access is the rudimentary requirements for the online education system. But in a developing country like Bangladesh, many students can't afford the online class infrastructure [5].

According to Internet World Stats's count, there were only 96,199,000 internet consumers in Bangladesh as of May 2020, implying $58.4 \%$ penetration of the total population. This poor penetration of internet access is one of the substantial constraints of online education. Besides, disproportionate access to technology and poor internet connection in rural areas also threaten the effectiveness of the online system [5]. As per the Ministry of Education, $60 \%$ of primary schoolgoing students come from rural areas, and $70 \%$ of secondary schools are positioned in these rural areas. Apparently, rural schools lack digital devices, competent teachers, and a strong internet connection, whereas, in urban areas, students are more likely to have the privilege of better technologies, internet access, etc. [6]. Aside from, urban-rural gap, students from lower-middle-class and low-income families struggle to avail online learning facilities. This discrepancy among students has generated a new debate, "Digital Divide" in social media and put the efficacy of online education in a questionable position [7]. Apart from students, teachers are also confronting hurdles in online classes. There is a scarceness of proficient and welltrained teachers in Bangladesh. Besides, some teachers lack internet literacy, availability of necessitated equipment, and logistics. The majority of them face inconveniencies in teaching on online platforms. They are also disquieted about 
the effectiveness of their teaching since they can't monitor students' class participation directly through online learning facilities [8].

Though educational institutions have shifted their classes to the online system, board exams (Higher Secondary Certificate, Secondary School Certificate), as well as university admission exams, have been suspended. Students have not got any welldefined guidelines about their higher studies, putting their academic careers in a tentative position [9]. A similar situation has also arisen for tertiary-level students, especially for public university students. In Bangladesh, public universities have not come to a decision regarding their exams, with few exceptions. As a result, students are grappling with session jam which not only hampers their academic lives and mental well-being but also affects their family. The majority of students in public universities derive from middle-class and poor backgrounds. If they lose one or two years of their academic lives due to session jam, it will encumber their parents financially [10]. Also, students in their final year are struggling with their graduation and stressed about the job market [11].

The rate of child marriage in Bangladesh has taken a steep rise owing to the closure of educational institutions [12]. Bangladesh had made tremendous development in diminishing child marriage before this pandemic [12], [13], but the rate of child marriage has risen to 220 percent throughout JulySeptember 2020 [12]. Prolonged school closure has made the parents insecure about their daughters' education, triggering child marriage [13]. According to experts, the situation can deteriorate if there is more deferral in reopening schools. Moreover, due to child marriage, the rate of school dropout is also escalating [12]. According to a report of Education Watch, $20 \%$ of primary school teachers, $29 \%$ of secondary school teachers, and $25 \%$ of guardians fear that the dropout rate will rise after the reopening of institutions. During this prolonged school closure, many students have got entangled in child labor to support their families economically, and it can compel students to drop out of schools after this pandemic. Also, child marriage is one of the major influences of the escalating rate of dropout [14].

Educational institutes not only provide academic guidelines but also secure the physical and mental well-being of students. Due to the extended school closures, children have lost the stable environment tendered by schools. In this pandemic, many families are facing an economic crisis, which has deteriorated their mental health. Consequently, children are vulnerable to child abuse as they are confined to homes. Research across the child protection agencies worldwide indicates that there has been reported an increased number of child abuse, child labor, sexual exploitation during this ongoing situation [15]. Reportedly, physically or mentally disabled children are at increased risk of child abuse as they necessitate extra care and attention, adding additional stress on the parents [16]. Besides, the augmented occurrence of child marriage, owing to the extended shutdown of schools, has led to the escalation of physical and sexual violence of young girls, teenage pregnancies, etc. [17].

The lockdown and closure of educational institutes have demonstrated negative impacts on students' academic performance, physical activity, psychological well-being, eating habits, etc. [18]. The impact of the extended break from school on students' distance learning is still indefinite [19]. It has been noticed that e-learning diminishes students' academic performance, especially in primary level students where handeye coordination is required [18]. Specifically, they are lagging in spelling skills and math computation. And these problems are more striking among children who are dealing with learning disorders [19]. A study revealed that $19 \%$ of primary and $25 \%$ of secondary level students are at the threat of learning loss owing to the closure of schools since March 2020 [20]. Also, due to the shutdown of schools, students can't perform extra-curriculum activities leading to their decreased physical activities [18]. They are leading a sedentary lifestyle; as a result, they are becoming prone to obesity and other chronic diseases like diabetes, cardiovascular diseases, and some types of cancers [21]. Besides, isolation in this stressful environment is also hampering children's sleep quality. Parents have expressed that their children have manifested anxiety, fear, and poor sleep quality with nightmare disorders [18].

The occurrence of undernutrition among children is greater in Bangladesh than in any other developing country [21]. Many children rely on the free food distributed in schools for nourishing nutrition. Due to the shutdown of institutes, they are losing out their reliable source of nutrition, triggering the prevalence of malnutrition [17]. On the other hand, several children have developed poor eating habits during this pandemic. Out of stress, they are devouring foods rich in sugar and carbohydrates excessively and gaining over-weight consequently [18]. It has also been reported that the out-ofschool environment contributes to excessive weight gain in childhood [22].

During this pandemic, there has been reported a notable upsurge in the screen time of students. The ongoing closure of educational institutes has disrupted students' daily schedules significantly [23]. This stay-at-home mandate has caused increased consumption of digital activities like social media, online gaming, or online classes. There has been a remarkable rise in the number of online gamers lately. Online gaming may promote socialization or stress reduction for the time being. Still, it may pose potential risks, including gaming disorder, unhealthy lifestyle, mental issues, reduction of face-to-face interaction, etc. [24]. In addition, during this pandemic, students are communicating and attaining information about their studies and ongoing COVID-19 situation through social media promoting excessive use of social media. Many studies demonstrated that excessive use of social media had been linked with poor psychological well-being, depression, anxiety, etc. [25]. Also, according to a survey, 30\% of children were abused online in Bangladesh during the COVID-19 period. It also revealed that $88 \%$ of respondents were exploited by strangers and $41 \%$ by their family members [26]. However, increased screen time may lead to an upsurge in the incidence of myopia by manipulating long-term behavioral changes [27].

The extended closure of educational institutes has impacted students' mental health eminently. According to a prior 
survey, there have been noted high levels of moderate to severe depression $(52.2 \%)$, anxiety $(58.1 \%)$. Stress $(24.9 \%)$ among tertiary level students in Bangladesh during the preCOVID-19 period. However, due to the prolonged break from studies, students may go through lonesomeness, distress, annoyance, tediousness, anxiety, and other emotions with their short and long-term effects. In short-term effects, they can experience sleeping problems, eating disorders, addictive behaviors, etc. These feelings may bring about hopelessness, frustration, depression, and even suicidal thoughts [28]. It has been reported that there were 14436 suicide cases in Bangladesh from March 2020 to February 2021, compared to 8462 suicide cases in 2019. The number of suicides is about $45 \%$ higher in the COVID-19 period than in normal time [29].

Educational institutes have continued to be closed in Bangladesh since March 2020. Reportedly, Bangladesh is the only country in South Asia where schools are closed at a stretch for over a year [30]. The government has postponed the reopening of educational institutes several times considering the safety of students which has generated frustration and anxiety among students. Students and parents have complained of disturbance in students' academic and personal lives owing to this extended shutdown. They are now desperate to recommence face-to-face classes and resume their

\section{Reference}

[1] S. Dutta and M. K. Smita, "The Impact of COVID-19 Pandemic on Tertiary Education in Bangladesh: Students' Perspectives," Open J. Soc. Sci., vol. 08, no. 09, pp. 53-68, Sep. 2020, doi: 10.4236/jss.2020.89004.

[2] "Coronavirus disease (COVID-19)." https://www.who.int/emergencies/diseases/novel-coronavirus2019 (accessed Jun. 02, 2021).

[3] “করোনা ভাইরাস ইনফো ২০১৯ - Coronavirus Disease 2019 (COVID-19) Information Bangladesh | corona.gov.bd." https://corona.gov.bd/ (accessed Jun. 02, 2021).

[4] M. Z. Ela et al., "Prolonged lockdown and academic uncertainties in Bangladesh: A qualitative investigation during the COVID-19 pandemic," Heliyon, vol. 7, no. 2, p. e06263, Feb. 2021, doi: 10.1016/j.heliyon.2021.e06263.

[5] M. G. Ramij and A. Sultana, "Preparedness of Online Classes in Developing Countries amid COVID-19 Outbreak: A Perspective from Bangladesh," SSRN Electron. J., Jun. 2020, doi: 10.2139/ssrn.3638718.

[6] R. Rafe, "COVID-19 deepens divide between Bangladesh's rural and urban students," Oct. 2020. https://www.dw.com/en/education-bangladesh/a-55358552 (accessed Jun. 01, 2021).

[7] M. A. Goni, “Closing digital divide in BD's online education," The Financial Express, Aug. 26, 2020.

[8] T. Asjad, "Teachers yet to be at ease with online classes," The Financial Express, Aug. 21, 2020.

[9] S. Aziz, K. M. M. Uzzal, and S. Aziz, "Covid-19 and university admission exams: A bangladesh perspective," $J$. Public health Res., vol. 9, no. S1, 2021, doi: 10.4081/jphr.2021.2017.

[10] P. K. Pandey, "Covid-19 and Potential Threat to Session Jams-508750,” daily sun, Sep. 29, 2020. normal lives [31]. Even, some educationalists also feel that schools and all other educational institutions should be reopened soon ensuring the safety of students and teachers and a two-year recovery plan should be implemented for learning loss [32].

\section{Funding}

The authors received no funding for this research.

\section{Conflict of Interest}

The authors declare no competing interest regarding this study that may arise from the third party

\section{Conclusion}

The impact of protracting closure of educational institutes on the future generation will be irreversible. It has affected students' academic ambitions, psychological health, physical health, and behavioral pattern adversely. Hence, we support the reopening of all educational institutions based on evidence for safeguarding the educational, physical, mental, social, and emotional well-being of the students. We also recommend more research to find a more adaptive education system, not just closing down educational establishments during any health crisis.

[11] J. Lee, "Mental health effects of school closures during COVID-19," Lancet Child Adolesc. Heal., vol. 4, no. 6, p. 421, 2020, doi: 10.1016/S2352-4642(20)30109-7.

[12] "School closure during covid-19 pandemic: Concerns over rising rate of school dropouts, child marriages," Oct. 2020. https://www.brac.net/latest-news/item/1291-schoolclosure-during-covid-19-pandemic-concerns-over-rising-rateof-school-dropouts-child-marriages (accessed Jun. 02, 2021).

[13] S. N. Sakib, "Bangladesh: Child marriage rises manifold in pandemic," Mar. 2021. https://www.aa.com.tr/en/asiapacific/bangladesh-child-marriage-rises-manifold-in-

pandemic/2184001 (accessed Jun. 02, 2021).

[14] "Children's right to education is at risk in the Covid era," Dhaka Tribune, Jan. 24, 2021.

[15] "No Education, No Protection: What school closures under COVID-19 mean for children and young people in crisis-affected contexts - World | ReliefWeb," Mar. 2021. https://reliefweb.int/report/world/no-education-no-protectionwhat-school-closures-under-covid-19-mean-children-andyoung (accessed Jun. 02, 2021).

[16] S. J. Lewis, A. P. S. Munro, G. D. Smith, and A. M. Pollock, "Closing schools is not evidence based and harms children," The BMJ, vol. 372. BMJ Publishing Group, Feb. 2021, doi: 10.1136/bmj.n521.

[17] "Adverse consequences of school closures." https://en.unesco.org/covid19/educationresponse/consequence s (accessed Jun. 02, 2021).

[18] D. I. Siachpazidou et al., "Action and Reaction of PrePrimary and Primary School-Age Children to Restrictions during COVID-19 Pandemic in Greece," J. Pers. Med., vol. 11, no. 6, p. 451, May 2021, doi: 10.3390/jpm11060451.

[19] A. Pavlovic et al., "Keeping children healthy during and after COVID-19 pandemic: meeting youth physical activity 
needs," BMC Public Health, vol. 21, Mar. 2021, doi: 10.1186/s12889-021-10545-x.

[20] "Covid: Bangladesh not reopening schools, colleges till May 29," Dhaka Tribune, May 15, 2021.

[21] S. Rahman, Z. S. Lassi, and S. M. S. Islam, "Risks to Bangladeshi children and young people during covid-19 outbreak," BMJ, vol. 369, Jun. 2020, doi: 10.1136/bmj.m2299. [22] E. S. Kim, Y. Kwon, Y. H. Choe, and M. J. Kim, "COVID-19-related school closing aggravate obesity and glucose intolerance in pediatric patients with obesity," Sci. Rep., vol. 11, p. 5494, 2021, doi: 10.1038/s41598-021-84766$\mathrm{W}$.

[23] V. A. Kovacs et al., "Physical activity, screen time and the COVID-19 school closures in Europe-An observational study in 10 countries," Eur. J. Sport Sci., 2021, doi: 10.1080/17461391.2021.1897166.

[24] D. L. King, P. H. Delfabbro, J. Billieux, and M. N. Potenza, "Problematic online gaming and the COVID-19 pandemic," J. Behav. Addict., vol. 9, no. 2, pp. 184-186, 2020, doi: 10.1556/2006.2020.00016.

[25] Y. Jiang, "Problematic Social Media Usage and Anxiety Among University Students During the COVID-19 Pandemic: The Mediating Role of Psychological Capital and the
Moderating Role of Academic Burnout," Front. Psychol., vol. 12, p. 76, 2021, doi: 10.3389/fpsyg.2021.612007.

[26] "Survey finds $30 \%$ children were abused online during pandemic," Dhaka Tribune, Feb. 28, 2021.

[27] C. W. Wong et al., "Digital Screen Time During the COVID-19 Pandemic: Risk for a Further Myopia Boom?," Am. J. Ophthalmol., vol. 223, pp. 333-337, 2021, doi: 10.1016/j.ajo.2020.07.034.

[28] M. S. Islam, M. S. H. Sujan, R. Tasnim, M. T. Sikder, M. N. Potenza, and J. van Os, "Psychological responses during the COVID-19 outbreak among university students in Bangladesh," PLoS One, vol. 15, no. 12, p. e0245083, 2020, doi: 10.1371/journal.pone.0245083.

[29] S. N. Sakib, "Bangladesh: Suicide claims more lives than coronavirus," Mar. 2021. https://www.aa.com.tr/en/asiapacific/bangladesh-suicide-claims-more-lives-thancoronavirus/2175200\# (accessed Jun. 02, 2021).

[30] S. A. Hamid, "Covid is not going away, so will school remain closed?," Prothom Alo, Mar. 29, 2021.

[31] K. N. Rahman, "For SSC, HSC students, uncertainty clouds road to the future," bdnews24.com, May 22, 2021.

[32] M. Ahmed, "A blueprint for school reopening and learning recovery," The Daily Star, Jan. 24, 2021. 